\title{
Brain-Derived Neurotrophic Factor Causes cAMP Response Element-Binding Protein Phosphorylation in Absence of Calcium Increases in Slices and Cultured Neurons from Rat Visual Cortex
}

\author{
Tommaso Pizzorusso,, ${ }^{1,2}$ Gian Michele Ratto, ${ }^{1}$ Elena Putignano, ${ }^{2}$ and Lamberto Maffei ${ }^{1,2}$ \\ 1/stituto di Neurofisiologia Consiglio Nazionale delle Ricerche, 56010 San Giuliano Terme, Italy, and 2Scuola Normale \\ Superiore, Piazza Cavalieri, 756126 Pisa, Italy
}

\begin{abstract}
Neurotrophins play a crucial role in the developmental plasticity of the visual cortex, but very little is known about the cellular mechanisms involved in their action. In many models of synaptic plasticity, increases in cytosolic calcium concentration and activation of the transcription factor CAMP response element-binding protein (CREB) are crucial factors for the induction and maintenance of long-lasting changes of synaptic efficacy. Whether BDNF modulates intracellular calcium levels in visual cortical neurons and the significance of this action for BDNF signal transduction is still controversial. We investigated whether CREB phosphorylation and calcium changes are elicited by acute BDNF presentation in postnatal visual cortical slices and cultures. We found that BDNF did not cause any calcium increase, but it induced robust CREB phosphorylation in neurons from both preparations. We further analyzed signal transduction and its dependency on calcium changes in cultured neurons. CREB phosphorylation required trkB activation because treatment with the trk inhibitor k252a completely
\end{abstract}

Neurotrophins (NTs) are key regulators of the plastic processes occurring during maturation of the visual cortex, but the cellular mechanisms mediating this action are still poorly understood (Katz and Shatz, 1996; Pizzorusso and Maffei, 1996; Huang et al., 1999; McAllister et al., 1999). Recent results suggest that the action of NTs on cortical plasticity could be attributable to the interaction between the intracellular signaling pathways activated by NTs and those that convert changes of visual experience into long-lasting changes in synaptic strength. A convergence between these two pathways could occur at several levels. For instance, an increase in cytosolic calcium is a necessary step for the induction of long-term potentiation (LTP) at hippocampal and cortical synapses (Bear and Malenka, 1994). Recent results obtained in cultivated neurons suggest that NTs can also acutely modulate calcium levels in the cell body (Berninger et al., 1993; Zirrgiebel et al., 1995; Finkbeiner et al., 1997; Li et al., 1998). The action of BDNF on intracellular calcium has been proposed to be mediated by the TrkB-induced activation of phospholipase $\mathrm{C} \gamma$ with conse-

\footnotetext{
Received Sept. 29, 1999; revised Jan. 21, 2000; accepted Jan. 27, 2000.

We are grateful to Lucia Pasti and Giorgio Carmignoto for assistance with the Nikon confocal microscope. We thank Regeneron for supplying human recombinant BDNF. This work was supported by Telethon project 934, MURST COFIN 97, and EEC contracts BMH4-CT96-1604 and BIO4-CT96-0774.

T.P. and G.M.R. contributed equally to this paper.

Correspondence should be addressed to Gian Michele Ratto, Istituto Neurofisiologia Consiglio Nazionale delle Ricerche, Via Alfieri 1, 56010 San Giuliano Terme, Italy. E-mail: gimmi@in.pi.cnr.it.

Copyright (C) 2000 Society for Neuroscience $\quad 0270-6474 / 00 / 202809-08 \$ 15.00 / 0$
}

blocked CREB phosphorylation. In agreement with the imaging experiments, we verified that calcium changes were not necessary for CREB activation because preincubation with BAPTA-AM did not diminish the level of CREB phosphorylation induced by BDNF stimulation. CREB phosphorylation was accompanied by gene expression, because we observed the upregulation of c-fos expression, which was also not affected by preincubation with BAPTA-AM. Finally, BDNF caused phosphorylation of mitogen-activated protein kinase (MAPK), and because the treatment with the MAPK inhibitor U0126 completely abolished CREB activation and c-fos upregulation, it is likely that both processes depend mainly on the MAP kinase pathway. These results indicate that MAPK and CREB, but not intracellular calcium, are important mediators of neurotrophin actions in the visual cortex.

Key words: brain-derived neurotrophic factor; cAMP response element-binding protein; phosphorylation; calcium; synaptic plasticity; visual cortex

quent production of $\mathrm{IP}_{3}$ and release of calcium from internal stores (Zirrgiebel et al., 1995; Li et al., 1998). Unfortunately, the observed calcium responses to NTs are extremely variable in size and kinetics, and negative results have also been reported (Gaiddon et al., 1996; Sakai et al., 1997). The interpretation of these variable results, possibly because of differences in culture conditions, is further complicated by the lack of imaging data obtained on acute slices.

Another possible site of interaction between neurotrophin- and plasticity-related pathways is represented by the transcription factor cAMP response element-binding protein (CREB). CREmediated transcription is important for memory and learning in different species such as Drosophila, Aplysia, and mouse (Silva et al., 1998). Furthermore, hippocampal slices from mice with reduced levels of CREB show an impairment in the maintenance of LTP (Bourtchuladze et al., 1994). Recent results show that CREmediated transcription is activated during monocular deprivation in the mouse visual cortex, suggesting that CREB could play a role in visual cortical plasticity (Pham et al., 1999). CREB is also an important regulator of gene expression induced by NTs (Finkbeiner et al., 1997). Indeed, BDNF causes the phosphorylation of CREB at the transcriptional regulatory site Ser-133 and its subsequent activation which, in conjunction with other interacting proteins, triggers gene transcription (Ginty et al., 1994; Bonni et al., 1995; Finkbeiner et al., 1997; McAllister et al., 1997; Silva et al., 1998).

A prerequisite to consider calcium and CREB as possible 


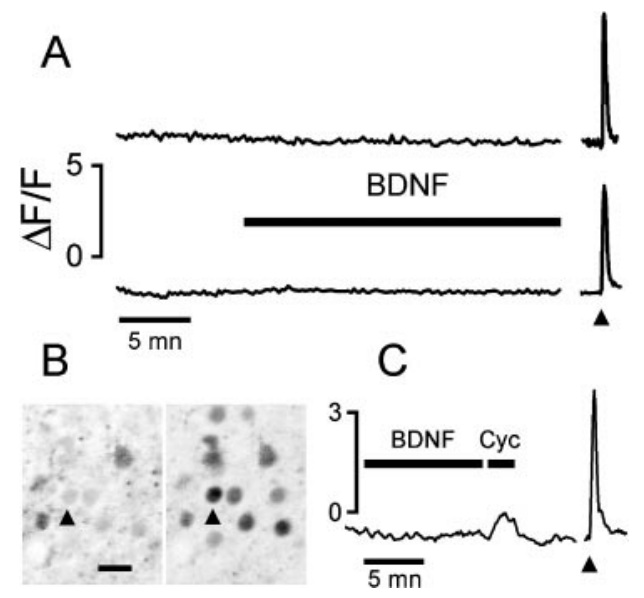

Figure 1. BDNF did not cause any detectable change of $\left[\mathrm{Ca}^{2+}\right]_{\mathrm{i}}$ in neurons of cortical slices. $A$, Fluorescence from the Ca-indicator fluo- 3 was integrated at the cell body of two neurons from a P8 and a P18 rat (top and bottom traces, respectively). The arrowhead indicates the stimulation with $20 \mu \mathrm{M}$ NMDA for $10 \mathrm{sec}$. $B$, The field is shown as recorded during the BDNF $(200 \mathrm{ng} / \mathrm{ml})$ presentation (left $)$ and at the peak of the NMDA response (right). The arrowhead points to the cell for which fluorescence is plotted on the top trace. Images are presented as negatives for better clarity. Scale bar, $20 \mu \mathrm{m}$. $C$, The lack of response to BDNF is not attributable to low sensitivity of the imaging because the small calcium increase induced by release from intracellular stores was easily detectable. Cyclopiazonic acid $(C y c ; 50 \mu \mathrm{M})$ caused a small but clearly resolved calcium transient in $49 \%$ of neurons $(n=57)$, whereas BDNF presentation did not cause any detectable calcium change. Arrowhead points to a $10 \mathrm{sec}$ puff of $20 \mu \mathrm{M}$ NMDA.

converging points between the signal transduction pathway of BDNF and synaptic plasticity machinery is that BDNF acutely modulates calcium levels and/or CREB activity in vivo in visual cortical neurons.

We investigated whether BDNF caused an increase of cytosolic calcium concentration and CREB phosphorylation in postnatal neurons of visual cortex slices. We found that BDNF did not alter intracellular calcium levels but strongly induced CREB phosphorylation. In addition we observed, in cultured neurons from the postnatal visual cortex, that CREB phosphorylation and c-fos upregulation are entirely dependent on mitogen-activated protein kinase (MAPK) activity and occur even after blocking of intracellular calcium changes.

\section{MATERIALS AND METHODS}

Slice preparation. Slices from the occipital neocortex (225- to $250-\mu \mathrm{m}$ thick) were prepared from hooded Long-Evans rats at postnatal days 8-23, as described (Edwards et al., 1989). The recording solution was composed as follows (in mM): $\mathrm{NaCl} 130, \mathrm{KCl} 3.1, \mathrm{~K}_{2} \mathrm{HPO}_{4} 1.0, \mathrm{NaHCO}_{3}$ 4.0, dextrose 5.0, $\mathrm{MgCl}_{2} 1.0, \mathrm{CaCl}_{2} 2.0, \mathrm{HEPES} / \mathrm{NaOH} 10$, ascorbic acid 1.0 , myo-inositol 0.5 , pyruvic acid $2,( \pm)$-sulfinpyrazone 0.02 , tetrodotoxin 0.001 , and glycine $0.01, \mathrm{pH} 7.2-7.4$. The solution was continuously oxygenated. Chemicals were purchased from Sigma (St. Louis, MO) unless otherwise indicated. Cutting solution differed only for concentrations of $\mathrm{MgCl}_{2}(4.0 \mathrm{~mm}), \mathrm{CaCl}_{2}(1.0 \mathrm{~mm})$, and for the omission of glycine.

$\left[\mathrm{Ca}^{2+}\right]_{i}$ imaging in slices. Fluo-3 or Indo-1 (Molecular Probes, Eugene, OR) were dissolved in $5 \mu$ l of a $3 \%$ solution of pluronic in DMSO. Slices were incubated in a $25 \mu \mathrm{M}$ solution of either fluo-3 or indo- 1 in oxygenated cutting solution for $1 \mathrm{hr}$ under continuous agitation at room temperature. Afterward, slices were transferred to recording solution for a period of rinsing. Fluo-3 imaging was performed on a Leica (Nussloch, Germany) TCS-NT confocal microscope while Indo-1 imaging was performed on a Nikon confocal microscope equipped with a UV laser. Slices were kept by a grid in a recording chamber and perfused at $\sim 3-4$ $\mathrm{ml} / \mathrm{min}$. Stimuli were NMDA (Tocris Cookson, Bristol, UK), recombi-
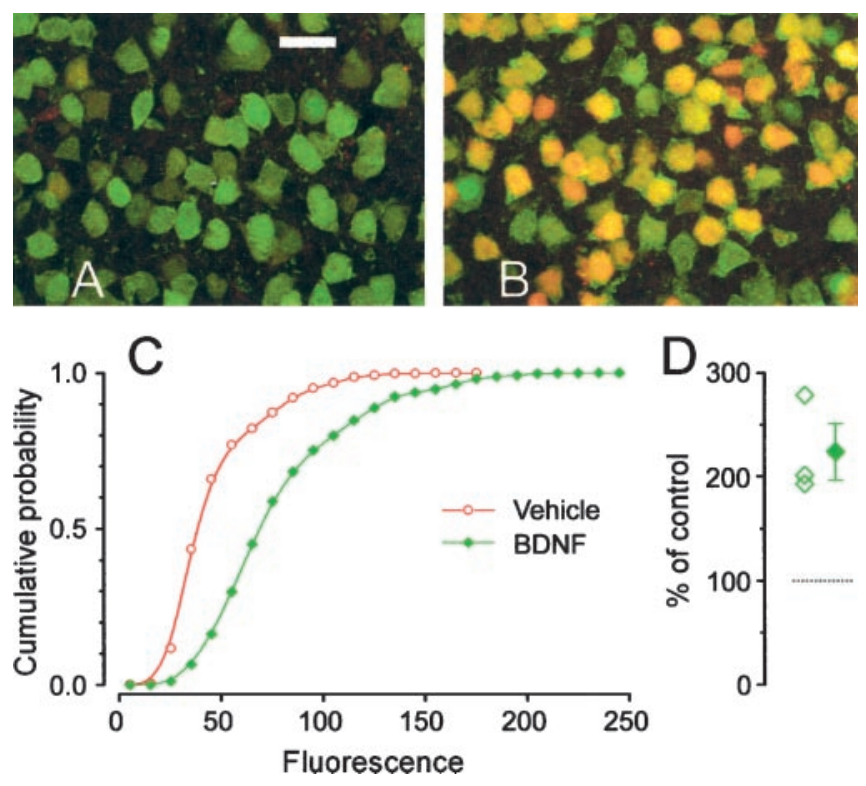

Figure 2. Cortical slices incubated in BDNF showed robust BDNFinduced CREB phosphorylation. $A$, Double immunostaining against the neuronal specific marker Neu (green) and pCREB (red). A low level of pCREB labeling was detectable in a few cells of control slices. Scale bar, $20 \mu \mathrm{m}$. B. Most neurons showed a strong pCREB signal in response to 1 hr stimulation with $200 \mathrm{ng} / \mathrm{ml}$ BDNF. $D$, The cumulative distribution of nuclear pCREB fluorescence in BDNF-treated (green, 4073 cells) slices is significantly shifted to the right with respect to controls (red, 3178 cells). $D$, Mean \pm SEM and single results of three experiments. Nuclear fluorescence was measured in 12 slices obtained from three different animals $(t$ test, $p<0.01)$.

nant human BDNF (gift of Amgen-Regeneron, Tarrytown, NY), cyclopiazonic acid, caffeine, thapsigargin, and L-glutamic acid solved in recording saline. Cyclopiazonic acid and thapsigargin solutions were obtained from $1000 \times$ stock solutions in DMSO. BDNF was freshly prepared for each experiment from single-use aliquots of a $10 \mathrm{mg} / \mathrm{ml}$ solution.

Cell culture. Cultures were prepared from 1-d-old hooded Long-Evans rat visual cortex. Briefly, after careful dissection from diencephalic structures and hippocampus, visual cortices were sliced and dispersed with trypsin $(0.25 \mathrm{mg} / \mathrm{ml} ; \mathrm{M}$. Brunelli, Milan, Italy). Cells were plated at $10^{6}$ cell/dish on poly-L-lysine-coated glass coverslips placed in $10 \mathrm{~cm}^{2}$ wells containing BME with $10 \%$ fetal calf serum and were maintained at $37^{\circ}$ in $5 \% \mathrm{CO}_{2}$. After $24 \mathrm{hr}$ in vitro, the medium was changed, and cytosine arabinof uranoside $(10 \mu \mathrm{M})$ was added.

$\mathrm{Ca}$ imaging in cultures. Coverslips were transferred in serum-free recording solution (composition as in slice experiments) for $4 \mathrm{hr}$ of serum deprivation. Afterward, cells were loaded in a $4 \mu \mathrm{M}$ solution of either fluo-3 or fura-2 (Molecular Probes) for $40 \mathrm{~min}$ at room temperature. Coverslips were placed in a recording chamber and perfused at $\sim 2$ $\mathrm{ml} / \mathrm{min}$. Fluo-3 imaging was performed on a Leica TCS-NT confocal microscope. Images were transferred to a custom-made software for data analysis.

Fura- 2 images were acquired (at $40 \times$ magnification, with a Zeiss Axioskop microscope) using an integrating CCD camera (PCO Sensi Cam) at excitation wavelengths of 340 and $380 \mathrm{~nm}$ and were stored every 2-4 sec. The Imaging Workbench software (Axon Instruments, Foster City, CA) was used to calculate the ratio of fluorescence at the two exciting wavelengths for each pixel within a cell boundary. Ratio was then averaged in areas corresponding to the soma and primary dendrites of cells in the field. The calcium level was calculated by the equation (Grynkiewicz et al., 1985):

$$
\left[\mathrm{Ca}^{2+}\right]=K_{\mathrm{D}} \cdot F_{0} / F_{\infty} \cdot\left(R-R_{\min }\right) /\left(R_{\max }-R\right),
$$

where $K_{\mathrm{D}}$ is the fura-Ca ${ }^{2+}$ binding constant $(\sim 220 \mathrm{nM})$. The parameters $R_{\min }, R_{\max }$ (the limiting values that the ratio can have at zero and saturating $\left[\mathrm{Ca}^{2+}\right]_{\mathrm{i}}$, respectively), and $F_{0} / F_{\infty}$ (the ratio of fluorescence at 


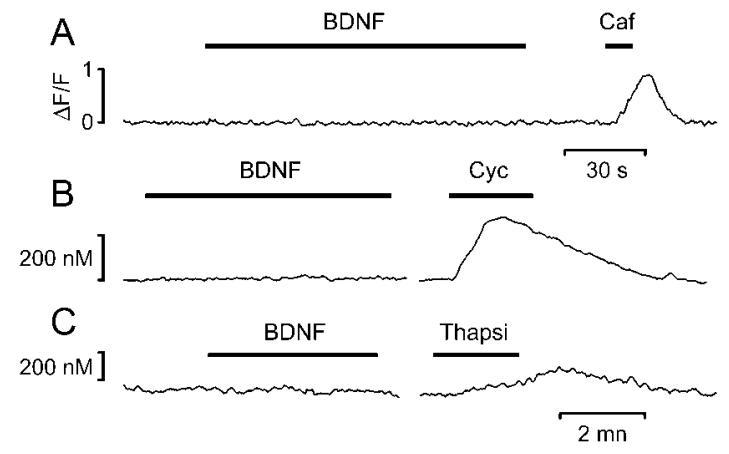

Figure 3. Calcium imaging from cultured neurons isolated from the visual cortex showed that acute presentation of BDNF did not cause any $\left[\mathrm{Ca}^{2+}\right]_{\mathrm{i}}$ increase. The same cells exhibited distinct responses to pharmacological agents that cause calcium release from stores. $A$, Fluo-3 imaging of a calcium transient evoked by $20 \mathrm{~mm}$ caffeine. $B, C$, Fura-2 imaging of calcium transients caused by $50 \mu \mathrm{M}$ Cyc or $1 \mu \mathrm{M}$ thapsigargin.

$380 \mathrm{~nm}$ with zero $\mathrm{Ca}^{2+}$ and saturating $\left[\mathrm{Ca}^{2+}\right]$ ) were measured as already described (Connor, 1986).

Immunostaining. Coverslips were processed as for calcium imaging. BAPTA-AM (Molecular Probes), U0126 (Promega, Madison, WI), and $\mathrm{k} 252 \mathrm{a}$ (Calbiochem, La Jolla, CA) were added $30 \mathrm{~min}$ before induction with BDNF. Drugs were solved at the final concentration from $1000 \times$ stock solutions in DMSO. Control coverslips were treated with drug vehicle.

At the end of the treatment cells were fixed (4\% paraformaldehyde for 5 min), rinsed in PBS, and blocked (PBS containing 0.4\% Triton, 10\% BSA). Primary antibodies (Neu-N, Chemicon, Temecula, CA, 1:1000; pCREB, New England Biolabs, Beverly, MA, 1:500; monoclonal phospho-p44/p42 MAPK (T202/Y204), New England Biolabs, 1:400; and c-fos, Oncogene Science, 1:1000) were diluted in blocking solution (BSA at $1 \%$ ) and reacted for $24-36 \mathrm{hr}$ at room temperature. c-fos and Neu-N were revealed using secondary antibodies labeled with fluorescein (Vector Laboratories, Burlingame, CA) or Alexa-488 (Molecular Probes), respectively. pCREB and pMAPK antibody were reacted with biotinylated secondary antibodies (Vector Laboratories) followed by ExtravidinCy3 (1:1000). Nuclei were stained with TOTO (4 $\mu \mathrm{M}$, Molecular Probes). The pCREB antibody also recognizes the phosphorylated form of the closely related protein ATF. After immunocytochemistry, coverslips were mounted in anti-fading agent (Vectashield; Vector Laboratories) on coded slides. Each trial was repeated at least three times on different cell preparations. Two or three coverslips were prepared for each experimental condition. From each coverslip at least three or four fields (500 by $500 \mu \mathrm{m}$ ) were acquired at the confocal microscope making sure to collect data from the best and brightest parts of the preparation. Each set of slides was acquired in a single session, to minimize fluctuation in laser output and degradation of the fluorescence. Images were processed with a custom-made software to measure nuclear fluorescence of each cell in the field. Astrocytes were excluded on the basis of their nuclear morphology. The code was broken only at the end of the data analysis.

Immunostaining of thick recording slices was performed by fixing $(6 \%$ paraformaldehyde in $0.1 \mathrm{M}$ Tris-buffered saline for $6 \mathrm{hr}$ at $4^{\circ}$ ), cryoprotecting, and cutting the slices (35 $\mu \mathrm{m}$ thickness). Free-floating sections were labeled and analyzed as described for cultured cells.

\section{RESULTS}

\section{BDNF does not cause calcium changes in neurons from slices of visual cortex}

Acute slices are a fundamental preparation to bridge the gap between experiments performed on cultured neurons and the situation occurring in vivo. Exposure of cortical slices to BDNF exerts short-term effects on neuronal responsiveness when assessed with physiological or biochemical techniques (Knusel et al., 1994; Akaneya et al., 1997; Carmignoto et al., 1997; Kinoshita et al., 1999; Schuman, 1999), however nothing is known on the acute effects of BDNF on the intracellular calcium concentration $\left(\left[\mathrm{Ca}^{2+}\right]_{\mathrm{i}}\right)$.
We studied the effect of BDNF on $\left[\mathrm{Ca}^{2+}\right]_{\mathrm{i}}$ of neurons from the visual cortex by means of confocal microscopy in acute slices loaded with the $\mathrm{Ca}^{2+}$ indicators fluo-3 or indo-1. Experiments performed with both indicators gave identical results, and therefore they have been pooled together. The $\left[\mathrm{Ca}^{2+}\right]_{i}$ changes were assessed on cell bodies and proximal dendrites. Spiking activity was suppressed by executing these and all the following experiments in TTX $(1 \mu \mathrm{M})$. A fraction of loaded cells were astrocytes, as it was demonstrated by their responsiveness to glutamate but not to NMDA (Pasti et al., 1997): these cells were excluded from data analysis.

We recorded 346 neurons from 22 slices obtained from 11 rats ranging in age from $\mathrm{P} 8$ to $\mathrm{P} 23$, and only $4(1.1 \%)$ neurons gave a transient response possibly related to $\mathrm{BDNF}$ presentation (BDNF doses ranging from $200 \mathrm{ng} / \mathrm{ml}$ up to $1 \mu \mathrm{g} / \mathrm{ml}$; stimulus duration, 5-35 min). Figure $1 A$ shows the lack of response of two neurons to a prolonged BDNF application. Typically, we have observed no transient or slow increase of $\left[\mathrm{Ca}^{2+}\right]_{i}$ after BDNF stimulation. To rule out a possible failure of detection, we verified that our imaging system was sensitive enough to reveal the elusive transient caused by the leak from internal stores unmasked by 50 $\mu \mathrm{M}$ cyclopiazonic acid (Cyc), a reversible inhibitor of the SERCA pumps (Seidler et al., 1989). Figure $1 C$ shows the calcium activity of a neuron (P11) that gave no detectable response to BDNF but that responded with a conspicuous transient after a brief stimulation with Cyc. This observation also suggests that BDNF presentation did not deplete intracellular calcium stores, which could be readily mobilized by $\mathrm{Cyc}$.

\section{BDNF causes CREB phosphorylation in slices of visual cortex}

Phosphorylation of CREB is a key element in the transduction of both activity- and neurotrophin-mediated gene expression (Bito et al., 1997; Finkbeiner et al., 1997; Silva et al., 1998). We assessed whether BDNF could induce phosphorylation of CREB using an antibody specific for CREB phosphorylated at Ser-133 (pCREB). Slices were perfused in a similar way to the imaging experiments, with either vehicle solution or a solution containing $200 \mathrm{ng} / \mathrm{ml}$ of BDNF. Figure 2, $A$ and $B$, shows that BDNF caused a strong CREB phosphorylation. Double blind quantification of these experiments is shown in Figure $2 C$ : the shift to the right of the cumulative probability of the fluorescence distribution is a sensitive indication of the fluorescence increase caused by BDNF. The average and single experiment results are summarized in Figure $2 D$. The failure in observing any $\left[\mathrm{Ca}^{2+}\right]_{i}$ change in these neurons following a protocol for BDNF stimulation identical to that used for assessing the effects of BDNF on CREB phosphorylation provides compelling evidence that the effect of BDNF on CREB occurs independently of any $\left[\mathrm{Ca}^{2+}\right]_{\mathrm{i}}$ change.

\section{BDNF does not cause a $\mathrm{Ca}$ increase in neurons from cultured cells from postnatal visual cortex}

Calcium imaging was performed on cells isolated from the postnatal visual cortex (explanted at P1) by using either a confocal microscope, in conjunction with the indicator Fluo-3, or a CCDbased imaging setup (Fura-2). These experiments confirmed the absence of a detectable calcium response after acute BDNF presentation (3-60 min). Out of 658 neurons recorded from eight different cultures (7-13 d in vitro), only nine neurons (1.4\%) gave a response that could be caused by BDNF presentation. As shown in slices, the lack of response is not likely to be attributable to a detection failure, because the imaging systems were sensitive 

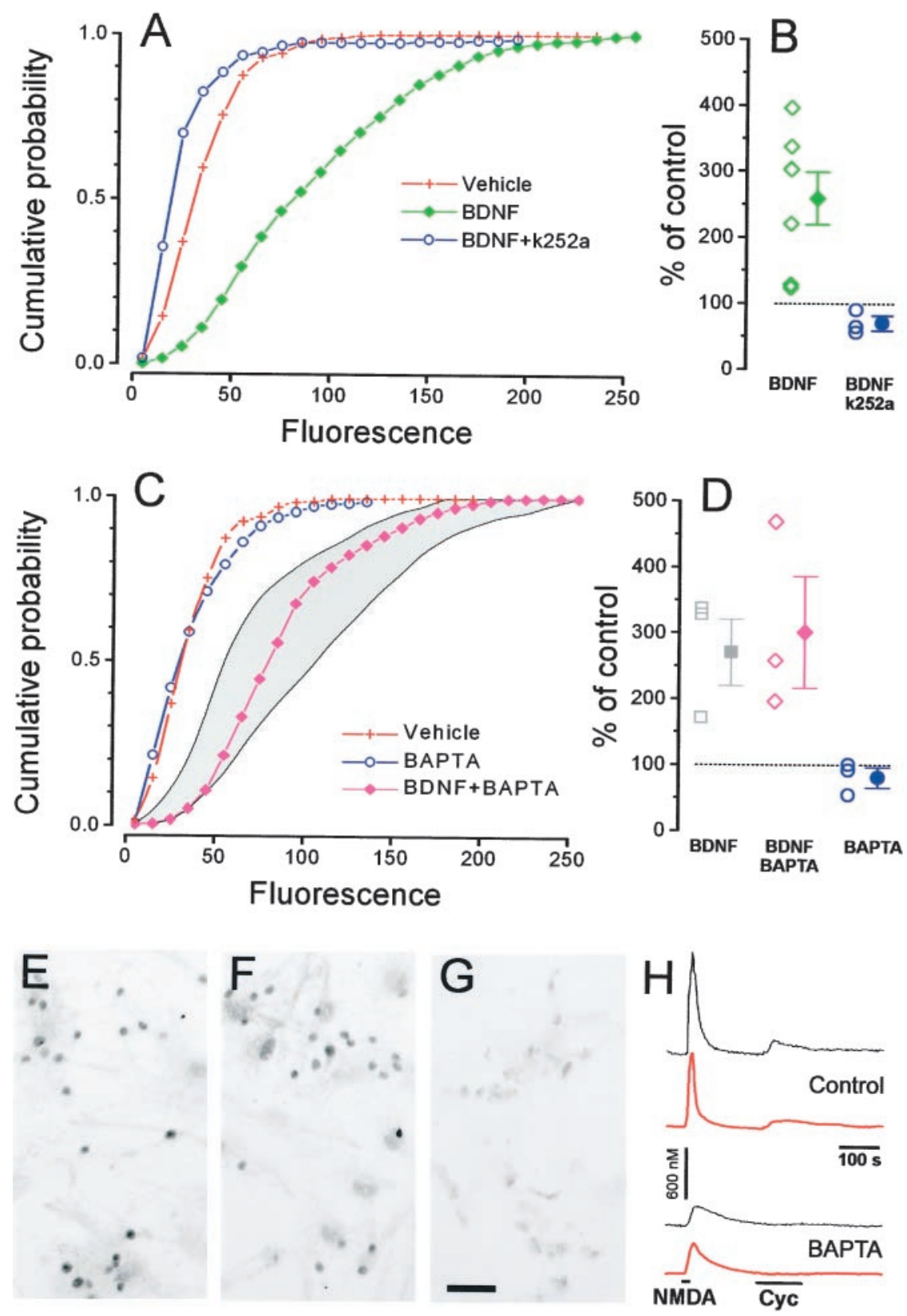

Figure 4. BDNF (15 min) induces CREB phosphorylation in cultured neurons from the visual cortex through a Trk-dependent and $\left[\mathrm{Ca}^{2+}\right]_{\mathrm{i}}$-independent pathway. $A, \mathrm{BDNF}$ (green, 1470 cells) increases pCREB staining with respect to the control (red, 811 cells). This effect is completely suppressed after incubation with the Trk inhibitor $\mathrm{k} 252 \mathrm{a}$ (blue, 310 cells). $B$, Mean \pm SEM and single results from separate experiments. (one-way ANOVA, $p<0.001$; Tukey's post hoc test, BDNF vs vehicle $p<0.05$; $2252 \mathrm{a}$ vs vehicle $p<0.05)$. $C$, Incubation with the cell-permeable calcium chelator BAPTA-AM (blue, 660 cells) did not cause any significant change in the basal level of CREB phosphorylation. The effect of BDNF on CREB phosphorylation is not diminished after BAPTA-AM incubation (magenta, 707 cells). The shaded area represents the confidence interval $(95 \%$ level, $t$ distribution) of pCREB staining distribution after induction with BDNF in normal conditions. $D$, Mean \pm SEM and single results for experiments in which BDNF was applied in sister cultures loaded with BAPTA-AM or control (one-way ANOVA, $p<0.001$; Tukey's post hoc test, BDNF + BAPTA vs vehicle, $p<0.05 ; \mathrm{BDNF}+\mathrm{BAPTA} v \mathrm{BDNF}$, not different, $p>0.05$; BAPTA vs vehicle, not different, $p>0.05$ ). $E-G$, Representative fields for BDNF, BDNF + BAPTA, and control. Scale bar, $50 \mu \mathrm{m}$. H, Fura-2 imaging on sister cultures of those used for pCREB immunostaining shows that BAPTA-AM incubation strongly slowed calcium responses induced by stimulation with $20 \mu \mathrm{M}$ NMDA and completely suppressed the calcium increases induced by $50 \mu \mathrm{M}$ Cyc. The black traces are recordings from single neurons, whereas the red traces are the average responses of neurons in two representative fields $(n=18$ cells above, $n=25$ below). enough to reveal the calcium increases attributable to mobilization from intracellular stores caused by caffeine $(20 \mathrm{~mm})$, Cyc (50 $\mu \mathrm{M})$, or thapsigargin (1 $\mu \mathrm{M}$; Fig. $3 A-C$, respectively).

\section{BDNF causes CREB phosphorylation and an increase of c-fos expression in cultured neurons from postnatal visual cortex}

Because the imaging experiments failed in showing any transient in $\left[\mathrm{Ca}^{2+}\right]_{\mathrm{i}}$ after BDNF stimulation, we asked whether other molecules of the signal transduction cascade were activated and whether gene expression was started independently from $\left[\mathrm{Ca}^{2+}\right]_{i}$ changes. Cultures were perfused, in identical conditions of the imaging experiments, with BDNF (50 ng/ml), control vehicle, or other molecules, fixed, and reacted with antibodies specific to pCREB, c-fos, or phosphorylated MAPK. The effects of BDNF induction were quantified double blind.

Immunostaining for pCREB (Fig. $4 E, G$ ) shows that BDNF stimulation induced a strong signal localized in the nucleus.
Quantification of the nuclear fluorescence demonstrates that BDNF caused a robust increase of pCREB (Fig. 4A,B) immunoreactivity. This effect was completely inhibited by preincubating the cultures with the tyrosine kinase inhibitor k252a (200 nM).

To exclude the possibility that CREB phosphorylation required some small calcium change that was left undetected under our imaging conditions, we analyzed CREB phosphorylation in cells loaded with the powerful calcium chelator BAPTA. Cultures were incubated with BDNF, BDNF after 30 min preloading with the membrane-permeant form of BAPTA (BAPTA-AM, $33 \mu \mathrm{M}$ ), or with BAPTA-AM only as a control. In neurons loaded with BAPTA, calcium changes caused by release from intracellular stores were virtually suppressed, and even changes caused by the influx of external calcium were strongly affected, as we have verified in a set of imaging experiments (Fig. 4H). pCREB staining caused by BDNF was virtually identical in presence or absence of BAPTA (Fig. $4 C-G$ ), strongly suggesting that calcium 

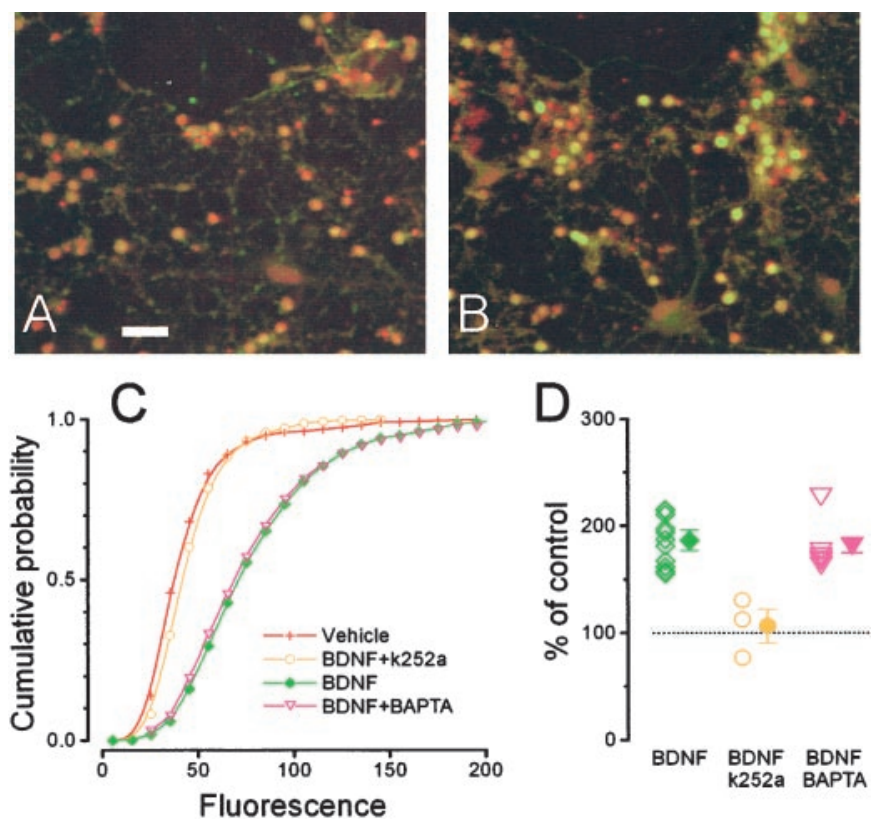

Figure 5. Stimulation with BDNF (1 hr) caused calcium-independent c-fos expression in cultured neurons from the visual cortex through a Trk-dependent pathway. $A$, Double staining with the nuclear staining TOTO (red) and a c-fos antibody (green). In control conditions only a weak green fluorescence is present in the neuron nuclei. Scale bar, $50 \mu \mathrm{m}$. $B$, After incubation with $50 \mathrm{ng} / \mathrm{ml} \mathrm{BDNF}$, most neurons became intensely positive for c-fos. $C$, The cumulative probability of the fluorescence distribution shows that BDNF (3543 cells) caused c-fos expression (green) and that this effect is completely suppressed by incubation with the Trk inhibitor k252a (k252a, 964 cells, yellow; vehicle, 2374 cells, red; one-way ANOVA, $p<0.005$; Tukey's post hoc test, BDNF vs vehicle, $p<$ 0.05; k252a vs vehicle, $p>0.05$ ). Loading neurons with BAPTA does not affect BDNF-induced c-fos expression (BDNF + BAPTA, 1523 cells, magenta; Tukey's post hoc test, $p>0.05)$. $D$, Mean \pm SEM and single results for all experiments. BAPTA alone did not modulate c-fos expression (92.8 $\pm 2.5 \%$ of control, 1021 cells; data not shown in figure).

is not a key effector in the pathway between TrkB activation and CREB phosphorylation.

Although phosphorylation of CREB is necessary for neurotrophin-induced gene expression, it is not always sufficient to initiate new transcription (Bonni et al., 1995). To determine whether CREB phosphorylation induced by BDNF is accompanied by gene transcription, we studied the induction of c-fos expression (Watson et al., 1999). As shown in Figure 5, $1 \mathrm{hr}$ stimulation with BDNF $(50 \mathrm{ng} / \mathrm{ml})$ caused a strong increase of the c-fos nuclear staining that was completely inhibited by preincubation with the trk inhibitor k252a (200 nM) and not affected by 30 min preincubation with BAPTA-AM $(33 \mu \mathrm{M})$.

\section{BDNF-induced CREB phosphorylation and c-fos expression require MAPK activation}

MAPK sits in a key position between the Trk/Shc/Ras pathway and CREB (Ginty et al., 1994; Xing et al., 1996, 1998). BDNF induced MAPK activation in visual cortical neurons, as shown by quantitative immunocytochemistry with a monoclonal antibody specific for dually phosphorylated MAPK at Thr-202 and Tyr-204 (pMAPK). Figure 6 shows that a 30 min incubation in BDNF (50 $\mathrm{ng} / \mathrm{ml}$ ) caused the appearance of pMAPK immunofluorescence in cytoplasm and nuclei. MAPK is activated when it is phosphorylated by MEK. The molecule U0126 is a potent and selective inhibitor of the kinasic activity of MEK, resulting in a block of
MAPK (Favata et al., 1998; Roberson et al., 1999). Preincubation with U0126 $(50 \mu \mathrm{M})$ completely blocked the increase of pMAPK staining after BDNF exposure $(p<0.01, t$ test, 78 cells, data not shown). Therefore, if the BDNF-induced phosphorylation of CREB was caused by the MAPK pathway only, incubation with U0126 should result in a block of CREB activation. Indeed, Figure 7 shows that a 30 min pretreatment with U0126 $(50 \mu \mathrm{M})$ completely suppressed the induction operated by a subsequent 15 min stimulation with BDNF. A similar pretreatment with U0126 abolished the BDNF-induced upregulation of c-fos (c-fos staining in BDNF-treated cells: $185.4 \pm 8.4 \%$ of vehicle-treated cells, 1539 cells, six experiments; c-fos staining in BDNF + U0126 cells: $84 \pm 5.5 \%$ of vehicle-treated cells, 1059 cells, six experiments; $t$ test, $p<0.001)$. These results demonstrate that, in our conditions, MAPK activation represents a necessary step for BDNF-induced CREB phosphorylation and c-fos expression.

\section{DISCUSSION}

Our results indicate that the acute exposure of postnatal visual cortical neurons to BDNF does not alter intracellular calcium levels but strongly induces CREB phosphorylation. CREB phosphorylation requires activation of MAPK and is accompanied by the induction of gene expression. The observation that BDNF does not elicit calcium transients, but induces CREB phosphorylation also in acute slices of visual cortex strengthens the transferability in vivo of these results.

NTs have been implicated in regulating the plastic processes occurring during the development of the visual cortex (Katz and Shatz, 1996; Pizzorusso and Maffei, 1996; McAllister et al., 1999; Lodovichi et al., 2000). The administration of NTs prevents the effects of the synaptic rearrangement caused by unbalanced activity caused by monocular deprivation (Maffei et al., 1992; Riddle et al., 1995; Galuske et al., 1996). In addition, it has been recently shown that the duration of the critical period for monocular deprivation is shortened by overexpression of BDNF in transgenic mice (Huang et al., 1999). The cellular mechanisms involved in the synaptic changes after monocular deprivation, which could also be influenced by NTs, are unknown. In cellular models of synaptic plasticity such as LTP and long-term depression, it has been shown that synaptic plasticity is the result of a complex chain of events involving calcium entry through NMDA receptors or voltage-gated calcium channels, activation of protein kinases, gene expression, and protein synthesis (for review, see Elgersma and Silva, 1999). At least for some of these elements, there is evidence supporting their involvement also in the plastic mechanisms implicated in the effects of monocular deprivation: CRE-mediated gene expression, an important effector of the cellular mechanisms of certain types of synaptic plasticity (Bito et al., 1996; Silva et al., 1998; Ahn et al., 1999; Glazewski et al., 1999), is induced by monocular deprivation in the cortical territory dominated by the nondeprived eye. This effect of monocular deprivation is present only during the critical period for plasticity (Pham et al., 1999). Our results show that NTs activate MAPK and CREB but do not induce calcium changes in cortical neurons from the postnatal visual cortex. Because both MAPK and CREB are also regulated by electrical activity and are necessary for plasticity, these molecules represent potential converging points between the cascades activated by NTs and electrical activity in the visual cortex. 

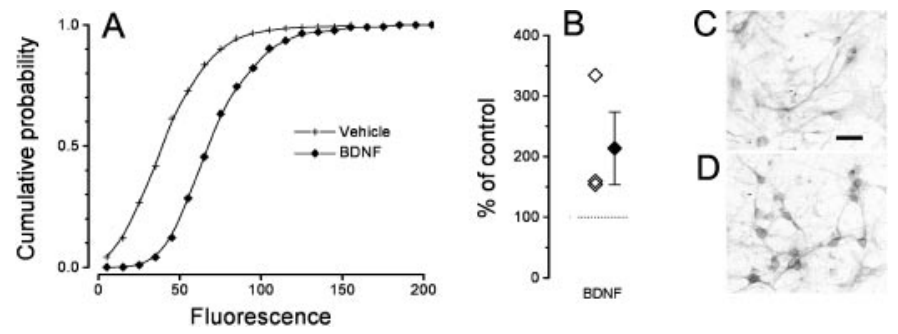

Figure 6. Acute stimulation with BDNF causes phosphorylation of MAPK. $A$ shows that a $30 \mathrm{~min}$ treatment with $50 \mathrm{ng} / \mathrm{ml}$ BDNF ( 896 cells) causes an increase of pMAPK immunofluorescence with respect to control (429 cells; $t$ test $p<0.05)$. B, Mean \pm SEM and single experiment data. $C, D$, Representative fields of pMAPK immunostaining in control $(C)$ and BDNF-treated cultures $(D)$. Note that pMAPK immunostaining is increased both in cell bodies and dendrites. Scale bar, $50 \mu \mathrm{m}$.

\section{BDNF induces CREB phosphorylation and c-fos expression in a calcium-independent way}

Our data show that postnatal visual cortical neurons do not respond with a calcium increase to the acute stimulation with BDNF. Other laboratories looked for calcium changes induced by BDNF in cultured neurons originating from various brain districts, and they reported data that displayed a great variability of amplitude and kinetics. Occasionally, negative results have also been observed (Berninger et al., 1993; Zirrgiebel et al., 1995; Gaiddon et al., 1996; Stoop and Poo, 1996; Finkbeiner et al., 1997; Sakai et al., 1997; Li et al., 1998). Because all these studies have been performed in culture it is difficult to evaluate to what extent this variability genuinely reflects differences in BDNF action occurring also in the intact animal or whether it has to be ascribed to various factors of the culture conditions. Indeed, the effects of NTs are strongly dependent on the cellular context of target cells (Ip and Yancopoulos, 1996; Sherwood et al., 1997), possibly because of differences in the modes of recruitment or in the availability of intracellular signaling molecules (Conti et al., 1997; Kaplan and Miller, 1997; Cattaneo and Pelicci, 1998). These considerations highlight the necessity of performing these experiments in conditions as close as possible to the in vivo situation

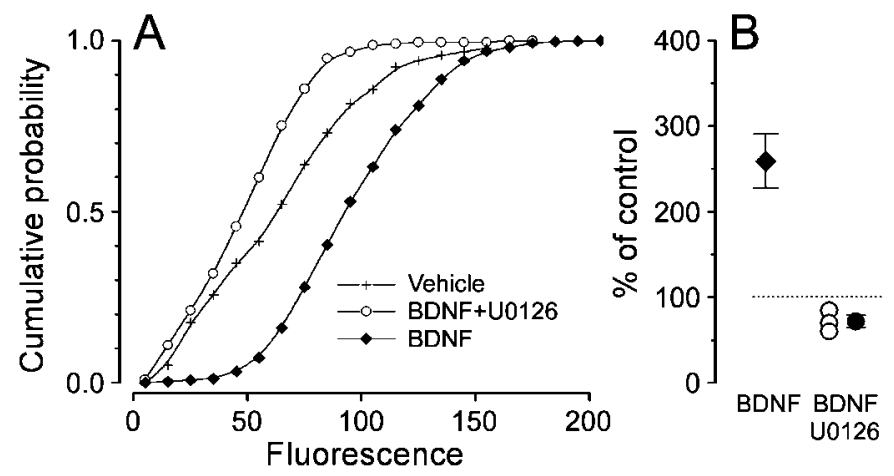

Figure 7. CREB phosphorylation requires MAPK activity. $A$, The increase of the immunostaining for pCREB with respect to control after BDNF stimulation is completely suppressed by preincubation with the MEK inhibitor U0126 (222 cells). $B$, Mean \pm SEM and single experiment data. pCREB immunofluorescence appears to be diminished by the U0126 treatment possibly because of block of basal levels of activation (one-way ANOVA, $p<0.001$; Tukey's post hoc test, BDNF + U0126 vs vehicle, $p<0.05$, BDNF $+\mathrm{U} 0126$ vs BDNF, $p<0.05)$. The average fluorescence increase induced by BDNF stimulation is reported (single data shown in Fig. 5). and prompted us to analyze BDNF action on intracellular calcium in neurons of acute cortical slices. The analysis performed in slices gave results consistent with those obtained in cultures, confirming that the acute stimulation with BDNF does not evoke calcium responses from postnatal neurons of the visual cortex.

In the same conditions in which BDNF failed to induce a calcium increase, we observed that acute BDNF stimulation induced a robust phosphorylation of CREB at Ser-133 and caused increased expression of c-fos. This effect is not secondary to an effect of BDNF on electrical activity because it was observed in presence of the sodium channel antagonist TTX. It has been shown that CREB phosphorylation is a necessary but not sufficient step for CREB-mediated gene transcription. However, the calcium-independent expression of c-fos after BDNF stimulation shows that, in our conditions, calcium changes are not necessary for BDNF-induced gene transcription.

\section{Role of MAP kinase in BDNF-induced CREB phosphorylation}

What is the machinery responsible for BDNF-induced CREB phosphorylation? It has been previously suggested that BDNF stimulates CREB phosphorylation and activation via at least two signaling pathways: by a Ras-dependent pathway and by a calcium/calmodulin-dependent kinase IV-regulated pathway that is activated by the release of intracellular calcium (Finkbeiner et al., 1997). Whereas activity-mediated CREB phosphorylation is quantitatively dependent on intracellular calcium increases (Ghosh and Greenberg, 1995; Deisseroth et al., 1996; Fields et al., 1997), our observations show that calcium changes are not necessary for BDNF-induced CREB phosphorylation and c-fos expression in visual cortical neurons. Indeed, the imaging experiments did not reveal any calcium change induced by BDNF both in slices and in cultured neurons. Furthermore, loading cortical neurons with BAPTA, a calcium chelator that blocks the calciumdependent induction of CREB phosphorylation elicited by depolarization (Deisseroth et al., 1996), did not affect BDNF-induced CREB phosphorylation and c-fos expression. The crucial element mediating BDNF-induced CREB phosphorylation and gene expression in visual cortical neurons is MAPK because its block completely abolishes CREB phosphorylation and c-fos expression induced by BDNF.

MAPK is an important molecule for plasticity in various brain areas (Kornhauser and Greenberg, 1997; Impey et al., 1999; Orban et al., 1999). Phosphorylated MAPK translocates to the nucleus where it activates, directly or through kinases of the Rsk family, transcription factors like Elk1 or CREB (Vossler et al., 1997; Impey et al., 1998; Sgambato et al., 1998). Furthermore, activated MAPK is also widely localized into the dendrites where it is likely to exert local actions (Sgambato et al., 1998). For instance, MAPK is required for the downregulation and internalization of the adhesion molecule Ap-CAM, a key step in the induction of long-term facilitation in Aplysia (Bailey et al., 1997). Furthermore, the action of MAPK can occur even at synaptic level, because it has been observed that MAPK directly phosphorylates synapsin I (Matsubara et al., 1996) in response to NTs (Jovanovic et al., 1996). The involvement of MAPK in synaptic plasticity and its strong activation by NTs in visual cortical neurons raise the possibility that MAPK could integrate plasticityrelated signals and NT-activated pathways, possibly even at the level of a single synapse. 


\section{REFERENCES}

Ahn S, Ginty DD, Linden DJ (1999) A late phase of cerebellar longterm depression requires activation of CaMKIV and CREB. Neuron 23:559-568.

Akaneya Y, Tsumoto T, Kinoshita S, Hatanaka H (1997) Brain-derived neurotrophic factor enhances long-term potentiation in rat visual cortex. J Neurosci 17:6707-6716.

Bailey CH, Kaang BK, Chen M, Martin KC, Lim CS, Casadio A, Kandel ER (1997) Mutation in the phosphorylation sites of MAP kinase blocks learning-related internalization of apCAM in Aplysia sensory neurons. Neuron 18:913-924.

Bear MF, Malenka RC (1994) Synaptic plasticity: LTP and LTD. Curr Opin Neurobiol 4:389-399.

Berninger B, Garcia DE, Inagaki N, Hahnel C, Lindholm D (1993) BDNF and NT-3 induce intracellular $\mathrm{Ca}^{2+}$ elevation in hippocampal neurones. NeuroReport 4:1303-1306.

Bito H, Deisseroth K, Tsien RW (1996) CREB phosphorylation and dephosphorylation: $\mathrm{a} \mathrm{Ca}^{2+}$ and stimulus duration-dependent switch for hippocampal gene expression. Cell 87:1203-1214.

Bito H, Deisseroth K, Tsien RW (1997) $\mathrm{Ca}^{2+}$-dependent regulation in neuronal gene expression. Curr Opin Neurobiol 7:419-429.

Bonni A, Ginty DD, Dudek H, Greenberg ME (1995) Serine 133phosphorylated CREB induces transcription via a cooperative mechanism that may confer specificity to neurotrophin signals. Mol Cell Neurosci 6:168-183.

Bourtchuladze R, Frenguelli B, Blendy J, Cioffi D, Schutz G, Silva AJ (1994) Deficient long-term memory in mice with a targeted mutation of the cAMP-responsive element-binding protein. Cell 79:59-68.

Carmignoto G, Pizzorusso T, Tia S, Vicini S (1997) Brain-derived neurotrophic factor and nerve growth factor potentiate excitatory synaptic transmission in the rat visual cortex. J Physiol (Lond) 498:153-164.

Cattaneo E, Pelicci PG (1998) Emerging roles for SH2/PTB-containing Shc adaptor proteins in the developing mammalian brain. Trends Neurosci 21:476-481.

Connor JA (1986) Digital imaging of free calcium changes and of spatial gradients in growing processes in single, mammalian central nervous system cells. Proc Natl Acad Sci USA 83:6179-6183.

Conti L, De Fraja C, Gulisano M, Migliaccio E, Govoni S, Cattaneo E (1997) Expression and activation of SH2/PTB-containing ShcA adaptor protein reflects the pattern of neurogenesis in the mammalian brain. Proc Natl Acad Sci USA 94:8185-8190.

Deisseroth K, Bito H, Tsien RW (1996) Signaling from synapse to nucleus: postsynaptic CREB phosphorylation during multiple forms of hippocampal synaptic plasticity. Neuron 16:89-101.

Edwards FA, Konnerth A, Sakmann B, Takahashi T (1989) A thin slice preparation for patch clamp recordings from neurones of the mammalian central nervous system. Pflügers Arch 414:600-612.

Elgersma Y, Silva AJ (1999) Molecular mechanisms of synaptic plasticity and memory. Curr Opin Neurobiol 9:209-213.

Favata MF, Horiuchi KY, Manos EJ, Daulerio AJ, Stradley DA, Feeser WS, Van Dyk DE, Pitts WJ, Earl RA, Hobbs F, Copeland RA, Magolda RL, Scherle PA, Trzaskos JM (1998) Identification of a novel inhibitor of mitogen-activated protein kinase kinase. J Biol Chem 273:18623-18632.

Fields RD, Eshete F, Stevens B, Itoh K (1997) Action potentialdependent regulation of gene expression: temporal specificity in $\mathrm{Ca}^{2+}$, cAMP-responsive element binding proteins, and mitogen-activated protein kinase signaling. J Neurosci 17:7252-7266.

Finkbeiner S, Tavazoie SF, Maloratsky A, Jacobs KM, Harris KM, Greenberg ME (1997) CREB: a major mediator of neuronal neurotrophin responses. Neuron 19:1031-1047.

Gaiddon C, Loeffler JP, Larmet Y (1996) Brain-derived neurotrophic factor stimulates AP-1 and cyclic AMP-responsive element dependent transcriptional activity in central nervous system neurons. J Neurochem 66:2279-2286.

Galuske RA, Kim DS, Castren E, Thoenen H, Singer W (1996) Brainderived neurotrophic factor reversed experience-dependent synaptic modifications in kitten visual cortex. Eur J Neurosci 8:1554-1559.

Ghosh A, Greenberg ME (1995) Calcium signaling in neurons: molecular mechanisms and cellular consequences. Science 268:239-247.

Ginty DD, Bonni A, Greenberg ME (1994) Nerve growth factor activates a Ras-dependent protein kinase that stimulates c-fos transcription via phosphorylation of CREB. Cell 77:713-725.

Glazewski S, Barth AL, Wallace H, McKenna M, Silva A, Fox K (1999)
Impaired experience-dependent plasticity in barrel cortex of mice lacking the alpha and delta isoforms of CREB. Cereb Cortex 9:249-256.

Grynkiewicz G, Poenie M, Tsien RY (1985) A new generation of $\mathrm{Ca}^{2+}$ indicators with greatly improved fluorescence properties. J Biol Chem 260:3440-3450.

Huang ZJ, Kirkwood A, Pizzorusso T, Porciatti V, Morales B, Bear MF, Maffei L, Tonegawa S (1999) BDNF regulates the maturation of inhibition and the critical period of plasticity in mouse visual cortex. Cell 98:739-755.

Impey S, Obrietan K, Wong ST, Poser S, Yano S, Wayman G, Deloulme JC, Chan G, Storm DR (1998) Cross talk between ERK and PKA is required for $\mathrm{Ca}^{2+}$ stimulation of CREB- dependent transcription and ERK nuclear translocation. Neuron 21:869-883.

Impey S, Obrietan K, Storm DR (1999) Making new connections: role of ERK/MAP kinase signaling in neuronal plasticity. Neuron 23:11-14.

Ip NY, Yancopoulos GD (1996) The neurotrophins and CNTF: two families of collaborative neurotrophic factors. Annu Rev Neurosci 19:491-515.

Jovanovic JN, Benfenati F, Siow YL, Sihra TS, Sanghera JS, Pelech SL, Greengard P, Czernik AJ (1996) Neurotrophins stimulate phosphorylation of synapsin I by MAP kinase and regulate synapsin I-actin interactions. Proc Natl Acad Sci USA 93:3679-3683.

Kaplan DR, Miller FD (1997) Signal transduction by the neurotrophin receptors. Curr Opin Cell Biol 9:213-221.

Katz LC, Shatz CJ (1996) Synaptic activity and the construction of cortical circuits. Science 274:1133-1138.

Kinoshita S, Yasuda H, Taniguchi N, Katoh-Semba R, Hatanaka H, Tsumoto T (1999) Brain-derived neurotrophic factor prevents lowfrequency inputs from inducing long-term depression in the developing visual cortex. J Neurosci 19:2122-2130.

Knusel B, Rabin SJ, Hefti F, Kaplan DR (1994) Regulated neurotrophin receptor responsiveness during neuronal migration and early differentiation. J Neurosci 14:1542-1554.

Kornhauser JM, Greenberg ME (1997) A kinase to remember: dual roles for MAP kinase in long-term memory. Neuron 18:839-842.

Li YX, Zhang Y, Lester HA, Schuman EM, Davidson N (1998) Enhancement of neurotransmitter release induced by brain-derived neurotrophic factor in cultured hippocampal neurons. J Neurosci 18:10231-10240.

Lodovichi C, Berardi N, Pizzorusso T, Maffei L (2000) Effects of neurotrophins on cortical plasticity: same or different? J Neurosci 20:21552165.

Maffei L, Berardi N, Domenici L, Parisi V, Pizzorusso T (1992) Nerve growth factor (NGF) prevents the shift in ocular dominance distribution of visual cortical neurons in monocularly deprived rats. J Neurosci 12:4651-4662.

Matsubara M, Kusubata M, Ishiguro K, Uchida T, Titani K, Taniguchi H (1996) Site-specific phosphorylation of synapsin I by mitogen-activated protein kinase and $\mathrm{Cdk} 5$ and its effects on physiological functions. J Biol Chem 271:21108-21113.

McAllister AK, Katz LC, Lo DC (1997) Opposing roles for endogenous BDNF and NT-3 in regulating cortical dendritic growth. Neuron 18:767-778.

McAllister AK, Katz LC, Lo DC (1999) Neurotrophins and synaptic plasticity. Annu Rev Neurosci 22:295-318.

Orban PC, Chapman PF, Brambilla R (1999) Is the Ras-MAPK signalling pathway necessary for long-term memory formation? Trends Neurosci 22:38-44.

Pasti L, Volterra A, Pozzan T, Carmignoto G (1997) Intracellular calcium oscillations in astrocytes: a highly plastic, bidirectional form of communication between neurons and astrocytes in situ. J Neurosci 17:7817-7830.

Pham TA, Impey S, Storm DR, Stryker MP (1999) CRE-mediated gene transcription in neocortical neuronal plasticity during the developmental critical period. Neuron 22:63-72.

Pizzorusso T, Maffei L (1996) Plasticity in the developing visual system. Curr Opin Neurol 9:122-125.

Riddle DR, Lo DC, Katz LC (1995) NT-4-mediated rescue of lateral geniculate neurons from effects of monocular deprivation. Nature 378:189-91.

Roberson ED, English JD, Adams JP, Selcher JC, Kondratick C, Sweatt JD (1999) The mitogen-activated protein kinase cascade couples PKA and $\mathrm{PKC}$ to CAMP response element binding protein phosphorylation in area CA1 of hippocampus. J Neurosci 19:4337-4348.

Sakai N, Yamada M, Numakawa T, Ogura A, Hatanaka H (1997) BDNF 
potentiates spontaneous $\mathrm{Ca}^{2+}$ oscillations in cultured hippocampal neurons. Brain Res 778:318-328.

Schuman EM (1999) Neurotrophin regulation of synaptic transmission. Curr Opin Neurobiol 9:105-109.

Seidler NW, Jona I, Vegh M, Martonosi A (1989) Cyclopiazonic acid is a specific inhibitor of the $\mathrm{Ca}^{2+}$-ATPase of sarcoplasmic reticulum. J Biol Chem 264:17816-17823.

Sgambato V, Pages C, Rogard M, Besson MJ, Caboche J (1998) Extracellular signal-regulated kinase (ERK) controls immediate early gene induction on corticostriatal stimulation. J Neurosci 18:8814-8825.

Sherwood NT, Lesser SS, Lo DC (1997) Neurotrophin regulation of ionic currents and cell size depends on cell context. Proc Natl Acad Sci USA 94:5917-5922.

Silva AJ, Kogan JH, Frankland PW, Kida S (1998) CREB and memory. Annu Rev Neurosci 21:127-148.

Stoop R, Poo MM (1996) Synaptic modulation by neurotrophic factors: differential and synergistic effects of brain-derived neurotrophic factor and ciliary neurotrophic factor. J Neurosci 16:3256-3264.
Vossler MR, Yao H, York RD, Pan MG, Rim CS, Stork PJ (1997) cAmp activates Map kinase and Elk-1 through a B-Raf- and Rap1-dependent pathway. Cell 89:73-82.

Watson FL, Heerssen HM, Moheban DB, Lin MZ, Sauvageot CM, Bhattacharyya A, Pomeroy SL, Segal RA (1999) Rapid nuclear responses to target-derived neurotrophins require retrograde transport of ligand-receptor complex. J Neurosci 19:7889-7900.

Xing J, Ginty DD, Greenberg ME (1996) Coupling of the RAS-MAPK pathway to gene activation by RSK2, a growth factor-regulated CREB kinase. Science 273:959-963.

Xing J, Kornhauser JM, Xia Z, Thiele EA, Greenberg ME (1998) Nerve growth factor activates extracellular signal-regulated kinase and p38 mitogen-activated protein kinase pathways to stimulate CREB serine 133 phosphorylation. Mol Cell Biol 18:1946-1955.

Zirrgiebel U, Ohga Y, Carter B, Berninger B, Inagaki N, Thoenen H, Lindholm D (1995) Characterization of TrkB receptor-mediated signaling pathways in rat cerebellar granule neurons: involvement of protein kinase C in neuronal survival. J Neurochem 65:2241-2250. 